\title{
Wine Oligosaccharides: Underutilized or Irrelevant? A Study into the Effects of Oligosaccharides on Wine Taste and Mouthfeel
}

\author{
Samuel Hoffman ${ }^{1}$, Quynh Phan $^{1} \&$ Elizabeth Tomasino ${ }^{1}$ \\ ${ }^{1}$ Department of Food Science and Technology, Oregon State University, Corvallis OR, USA \\ Correspondence: Elizabeth Tomasino, Department of Food Science and Technology, Oregon State University, \\ Corvallis OR, USA. Tel: 1-541-737-4866. E-mail: Elizabeth.Tomasino@oregonstate.edu
}

Received: October 2, 2021

Accepted: October 20, $2021 \quad$ Online Published: October 25, 2021

doi:10.5539/jfr.v10n5p60

URL: https://doi.org/10.5539/jfr.v10n5p60

\begin{abstract}
The taste and mouthfeel of a wine are two of the most important aspects of wine tasting. However, while much is known about phenolic compounds and other macromolecules direct effects on wine taste and mouthfeel, little is known about other wine compounds such as oligosaccharides. This experiment uses Fructo-oligosaccharide (FOS) and Galacto-oligosaccharide (GOS) at two different concentrations, $450 \mathrm{mg} / \mathrm{L}$ and $900 \mathrm{mg} / \mathrm{L}$ within a simple model wine matrix. A model matrix was used to control for any unknown interactions between oligosaccharides and the multitude of wine components. Oligosaccharides were added individually to the model wine matrix at each concentration to create four treatments. Triangle tests were performed on all treatments against the control base model wine and between the high and low concentrations of each oligosaccharide treatment. Following the triangle tests, each treatment and the control underwent descriptive analysis (DA) using line intensity scales for sweetness, bitterness, astringency, acidity, and viscosity. Triangle test results revealed a significant difference only between the FOS450 and FOS900 samples. The wine matrix was made more complicated by adding polyphenols and still, none of the four oligosaccharide treatment groups were found to be significantly different. DA found no significant differences for the five attributes but did show clear trends in increased sweetness and acidity, decreased bitterness, as well as changes to astringency and viscosity. This suggests there may be more complex interactions happening within the mouth. However, given the lack of significant results in the simple wine model and the more complex wine model wine, any complex interactions between oligosaccharides and other wine compounds are likely to be minimal.
\end{abstract}

Keywords: galacto-oligosaccharides, Fructo-oligosaccharides, triangle tests, polyphenols, descriptive analysis

\section{Introduction}

Wine is an inherently complex system consisting of hundreds of different components that potentially impact organoleptic perception. Oligosaccharides are just one class of compounds that are present in wine and are generally defined as carbohydrates with low degrees of polymerization, specifically a mean degree of polymerization (mDP) of 2-20 units (BeMiller, 2019). Oligosaccharides consist of monomeric saccharides covalently linked via glycosidic bonds. Finished wines of differing varietals have different oligosaccharide compositions (Apolinar-Valiente et al., 2015). While the composition and concentration of oligosaccharides has been found to vary (Bordiga et al., 2012; Boulet et al., 2016), the potential impact on wine sensory perception has yet to be investigated thoroughly.

Current understanding shows that oligosaccharide concentration can vary between $50-550 \mathrm{mg} / \mathrm{L}$ and is dependent on several factors (Bordiga et al., 2012; Boulet et al., 2016). They originate from both grape and yeast cell walls (Chong et al., 2019) and differences in composition and concentration are due to grape cultivar, grape ripeness, terroir, enzymatic activity, winemaking, and vineyard management practices (Apolinar-Valiente et al., 2013, 2014, 2015; Bordiga et al., 2012; Ducasse et al., 2010, 2011; Vicens et al., 2009; Zietsman et al., 2015). The sheer number of factors known to affect the composition and concentration of oligosaccharides presents challenges in understanding how to alter oligosaccharide content in wine and how oligosaccharide modification might impact wine quality.

Current understanding of oligosaccharides on wine sensory perceptions is quite limited to date. Research has shown an impact on astringency perception and its relation to the presence of galactose and mannose within the oligosaccharide fraction of wine (Quijada-Morín et al., 2014). Astringency is defined as an overall drying, 
puckering or rough sensation within the mouth (Huang \& Xu, 2021). While astringency is an important aspect within wine sensory, it is only one attribute within an enormous array of sensory perceptions. In addition to wine taste and aroma, mouthfeel is generally difficult to understand. It is the result of multiple tactile oral stimulations and is understood by consumers as "a holistic multisensory perception of flavour" (Laguna et al., 2017). While astringency is the most heavily researched characteristic, there are many other descriptors used for wine mouthfeel such as drying, puckering, gritty, and hot (Gawel et al., 2000; Pickering \& Demiglio, 2008).

The sensory impact of oligosaccharides on wine is mostly unknown, but oligosaccharides of various types have been linked to other organoleptic responses in other food systems such as low-fat yogurt. Organoleptic testing of oligosaccharides in water demonstrated that the compounds can alter sweetness, although the impact is dependent on concentration, degree of polymerization, type of oligosaccharide, and chemical linkage (Lapis et al., 2014, 2016; Low et al., 2017; Pullicin et al., 2017, 2019; Ruiz-Aceituno et al., 2018). Additionally, some connections have been found for oligosaccharides effects on other mouthfeel characteristics but are typically dependent on the food system in which they are evaluated. For example, inulin when added to low-fat yogurt was described as "thick", "airy" and "sticky", depending on mDP and concentration (Kip et al., 2006).

Previous studies investigating oligosaccharide mouthfeel perception in wine analyzed wine samples for oligosaccharide make up and correlated the analyses with sensory results (Apolinar-Valiente et al., 2015; Bordiga et al., 2012). While this approach helps gain an initial understanding of the mechanisms at work, wine is simply too complex to gain a completely accurate understanding from this method alone. The present study was separated into three distinct tests. The first investigated if adding different oligosaccharide types and concentrations to a simple model wine solution resulted in perceivable taste and/or mouthfeel differences. The second test aimed to quantify any differences found in the initial triangle tests via descriptive analysis and to determine how the oligosaccharides influence perception. The third experiment explored potential taste and mouthfeel differences due to oligosaccharides when combined with compounds known to impact mouthfeel perception. Polyphenols influence wine mouthfeel, specifically perceived astringency (Ferrer-Gallego et al., 2014). This test used polyphenols in addition to oligosaccharides of different types and concentrations to investigate the impact on taste and mouthfeel perception.

Overall, these three experiments investigate oligosaccharide influence on taste and mouthfeel within a simple and more complex system, quantify those differences and relate them with specific attributes. Knowledge of compositional aspects that cause specific sensory attributes are key when trying to achieve or maintain specific qualities in wine, particularly when each year the starting material, grapes, may be different. The causes of specific mouthfeel attributes are largely unknown, and this work aims to provide more information in this area.

\section{Method}

\subsection{Chemicals}

Fructo-oligosaccharide (FOS) and Galacto-oligosaccharide (GOS) were used as mouthfeel stimuli. The FOS used is a commercially available dry powder containing at least 95\% Fructo-oligosaccharides (NUTRAFLORA® P-95, soluble prebiotic fiber, Ingredion, Westchester, Illinois, USA). The FOS powder consisted of oligosaccharide chains of three different degrees of polymerization, with the remaining percentage consisting of fructose, glucose, and sucrose. The sample provided for the study contained fructo-oligosaccharides at the following concentrations: DP3 36.1\%, DP4 50.5\%, and DP5 10.6\%, with average molecular weight of $490.90 \mathrm{~g} / \mathrm{mol}$. The GOS sample used is a commercially available syrup containing at least $68 \%$ galacto-oligosaccharides (Manufacturer requests omission from publication). The sample provided had an exact concentration of GOS of $71.6 \%$, with the remainder of the syrup being comprised of lactose at $24 \%$, and glucose + galactose at $4 \%$. The degree of polymerization of the oligosaccharide fraction of the GOS sample was DP2 31\%, DP3 38\%, DP4 18\%, DP5 8\%, and DP6 5\% with an average molecular weight of $533.63 \mathrm{~g} / \mathrm{mol}$. Both samples underwent preliminary tasing at concentrations higher than experimental values to ensure none of the residual shorter chain sugar molecules created noticeable sweetness (data not shown).

\subsection{Wine Matrix}

The base model wine consisted of $12 \%$ (v/v) ethanol (Everclear, Luxco, St. Louis, MO, USA) and $4 \mathrm{~g} / \mathrm{L}$ tartaric acid (Modernist Pantry, Eliot, MO, USA) in deionized water and was adjusted to $\mathrm{pH} 3.5$ using $0.5 \mathrm{M}$ sodium hydroxide. The base model wine was created in five-gallon glass carboys three days prior to testing and stored at $4^{\circ} \mathrm{C}$ until use.

\subsection{Sensory Analysis}

Approval for work was granted by Institutional Review Board at Oregon State University (IRB-2020-0610). 
Inclusion criteria for panelists was individuals who consumed 1 glass of wine a week on average. Individuals suffering from taste deficits and other oral disorders, oral lesions, canker sores, or wine allergies were excluded from participation. Smokers, pregnant persons, and individuals with tongue, lip, or cheek piercings were also excluded.

90 eligible panelists comprised of 24 male, 65 female, and 1 non-binary person ages 21 to $60+$ attended the initial triangle test panel. Panelists were told they would be evaluating wine and/or model wine solutions that contain different additions. From the 90 participants of the triangle tests, 22 panelists were invited back for the descriptive analysis. Of those 22 participants, 4 were male, 18 were female, and ages ranged from 21 to $60+$. The second triangle test consisted of 75 panelists comprised of 14 males, 61 females, ages 21 to 60+. All panels were conducted in the Arbuthnot Dairy Center on the OSU Campus (Corvallis, OR). Compusense ${ }^{\circledR}$ Cloud Software (Version 21.0.7773.192939) was used to administer each test. The testing room was held at $20-22^{\circ} \mathrm{C}$ and two Winix Plasmawave air purifiers (Winix, Vernon Hills, IL, USA) were used to ensure air quality. Custom built white plastic tabletop tri-folds $(61 \mathrm{~cm} \times 71 \mathrm{~cm}$ center, $61 \mathrm{~cm} \times 65 \mathrm{~cm}$ sides) were used to create individual booths for panelists. The room was a mix of artificial and natural light. All flights were served in black INAO wine glasses (Lehmann glass, Kiyasa Group, New York, NY, USA). Panelists were instructed to wear a foam-padded nose clip (Biotronics, Davie, FL, USA) during each triangle test. Panelists were provided with spit cups for expectorating samples and a $1 \mathrm{~g} / \mathrm{L}$ pectin (Modernist Pantry, Eliot, MO, USA) rinse to use between samples. A high-speed immersion blender (Mueller Austria Ultra-Stock, City of Industry, CA) was used to suspend the pectin in deionized water.

\subsection{Stimuli}

The stimuli treatments consisted of two different oligosaccharide groups, FOS and GOS, at two different concentration levels, $450 \mathrm{mg} / \mathrm{L}$ and $900 \mathrm{mg} / \mathrm{L}$. FOS and GOS were selected as they are both commercially available as food grade products. GOS is naturally occurring within wine (Osborne et al., 2019), while FOS can be produced by yeast, dependent upon yeast strain and fermentative conditions (Deffert et al., 2017). $450 \mathrm{mg} / \mathrm{L}$ was selected because previous studies have shown this is the average oligosaccharide concentration in Pinot noir (Osborne et al., 2019). $900 \mathrm{mg} / \mathrm{L}$ was selected to see if greatly increasing the concentration of oligosaccharides influenced taste and mouthfeel. To prepare samples for sensory analysis, the model wine matrix was taken from the cooler and dispensed into $750 \mathrm{~mL}$ bottles (Tricor, St. Louis, MO, USA) and closed with screwcaps (Amcor, Zürich, Switzerland) no more than 24 hours before the panel. For the control treatment no other compounds were added to the base model wine matrix. Both FOS and GOS were added to $500 \mathrm{~mL}$ of model wine via gentle stirring (no solubility difficulties due to low $\mathrm{pH}$ noticed), resulting in stock solutions with the concentration of $16.875 \mathrm{~g} / \mathrm{L}$ for each oligosaccharide. The stock solutions of each oligosaccharide were then added to bottles to create the four treatments: FOS450, FOS900, GOS450, and GOS900. The solutions were added to the base model wines in bottle no more than 24 hours prior to the day of the panel.

\subsection{Initial Triangle Test}

Triangle tests were conducted in accordance with the ISO 4120:2004(E) method (ISO 4120, 2004). Each panelist received six different triangle tests, four tests compared each of the treatment groups against the control, one compared FOS450 to FOS900, and another compared GOS450 to GOS900. Flights were presented in a randomized order and treatments presented within the flights were presented in a balanced order. There was a 60-second break between each triangle test, during which panelists were instructed to rinse their palate with the pectin rinse. Panelist wore nose clips while tasting and were only allowed to remove the clips during breaks between tests.

\subsection{Descriptive Analysis}

Descriptive analysis was performed using $100 \mathrm{~mm}$ line intensity scales for five different taste/mouthfeel characteristics. Training for descriptive analysis took place over two, one-hour training sessions. Panelists were trained on sweetness, bitterness, viscosity, astringency, and acidity standards. Initial concentrations of training standards were selected to encompass a wide range of responses for each attribute because of the limited knowledge about the effects of oligosaccharides and the desire to encompass all possible responses. Each training standard underwent preliminary testing via Check-All-That-Apply (CATA) to ensure consumers associated the standard with the given attribute (data not shown). Definitions of each attribute were provided during training and during the descriptive analysis (Table 1). For the first training session, panelists were presented with a taste or mouthfeel standard, the definition of the taste or mouthfeel attribute, and the corresponding location that the standard would be placed on the line scale. In the second training session, panelists were presented with training standards blind and were asked to score the samples on the line scales for 
each attribute to ensure panelists understood the scaling. Panelists wore nose clips while evaluating samples for both training sessions. Between each sample set, panelists had a 60-second break during which they were instructed to rinse their palate with the pectin rinse.

Descriptive analysis took place over two, 1-hour sessions. Panelists evaluated nine model wine samples at each session. The wines were presented in a random order and all treatments were presented at least once per session. All samples were evaluated in triplicate by each panelist over the 2-day panel. Characteristics evaluated were sweetness, bitterness, viscosity, astringency, and acidity. Panelists were instructed to put on nose clips, taste each sample and rate the sample on the five attributes using their corresponding line scales. Line scales ranges from "not _ " to "very __ " for each given attribute. The attribute definition from training was provided above the corresponding line scale to help increase memory recall. Panelists were also provided a scale labeled "Other" to evaluate the sample on an attribute not previously presented. Panelists were instructed to write in the attribute they used for the "Other" scale. Panelists had 60 -second breaks between each sample and were instructed to rinse their palate with the provided pectin rinse during the break.

\subsection{Phenolic Triangle Tests}

The third experiment followed the same procedure as the initial triangle tests, except those panelists received only four different triangle tests, each comparing the treatment groups to the control. The control contained 800 $\mathrm{mg} / \mathrm{L}$ of polyphenols in the base model wine. This concentration of polyphenols was selected from the results following internal testing of 126 commercially available Pinot Noir wines, via MCP Assay (Sarneckis et al., 2006) (data not shown). The polyphenols were added by grinding grape seed extract (Masquelier's Tru-Opc, Nature's Way Brands, Green Bay, WI) into a fine powder, weighing out the necessary amount, and dissolving it in the base model wine solution. These polyphenols were chosen to represent wine astringency based on preliminary tastings (data not shown).

Table 1. Descriptive analysis training standards and definitions

\begin{tabular}{|c|c|c|c|}
\hline Attribute & Compound & Concentration & Definition \\
\hline Sweetness & Sucrose & $\begin{array}{l}\text { Low: } 25 \mathrm{~g} / \mathrm{L} \\
\text { High: } 75 \mathrm{~g} / \mathrm{L}\end{array}$ & $\begin{array}{l}1 \text { - Being one of the five basic taste sensations that is } \\
\text { usually pleasing to the taste and typically induced } \\
\text { by sugars (Merriam-Webster, n.d.) } \\
2 \text { - In beverages: containing a sweet ingredient = } \\
\text { not dry (Merriam-Webster, n.d.) }\end{array}$ \\
\hline Bitterness & Caffeine & $\begin{array}{l}\text { Low: } 0.5 \mathrm{~g} / \mathrm{L} \\
\text { High: } 1 \mathrm{~g} / \mathrm{L}\end{array}$ & $\begin{array}{l}\text { Intensity of bitter taste perceived in the } \\
\text { mouth (Sparrow et al., 2016) }\end{array}$ \\
\hline Astringency & Aluminum Sulfate & $\begin{array}{l}\text { Low: } 0.4 \mathrm{~g} / \mathrm{L} \\
\text { High: } 1 \mathrm{~g} / \mathrm{L}\end{array}$ & $\begin{array}{l}\text { Intensity of the drying and mouth puckering } \\
\text { sensation in the mouth (Sparrow et al., 2016) }\end{array}$ \\
\hline Viscosity & Carboxymethyl Cellulose & $\begin{array}{l}\text { Low: } 2 \mathrm{~g} / \mathrm{L} \\
\text { High: } 4 \mathrm{~g} / \mathrm{L}\end{array}$ & $\begin{array}{l}\text { Perception of body, weight, or thickness } \\
\text { of the wine in the mouth (Sparrow et al., 2016) }\end{array}$ \\
\hline Acidity & Tartaric Acid & $\begin{array}{l}\text { Low: } 0.25 \mathrm{~g} / \mathrm{L} \\
\text { High: } 1 \mathrm{~g} / \mathrm{L}\end{array}$ & $\begin{array}{l}\text { Intensity of the acid taste perceived } \\
\text { in the mouth (Williamson, 2013) }\end{array}$ \\
\hline
\end{tabular}

\subsection{Statistical Analysis}

Statistical analysis was performed on triangle tests by bimodal distribution using ISO4120:2004(E) method Table A.1, then confirmed via Z-test on proportion. Z-scores and p-values are presented in Table 2 and Table 3. Analysis of Variance (ANOVA) was performed on descriptive analysis results using XLSTAT (XLStat 2020.3.1 Sensory Package, Addinsoft, Paris, France) and are displayed in Figure 1.

\section{Results}

\subsection{Triangle Tests}

Triangle test results shown in Table 2 and Table 3 indicate that none of the four treatments were significantly different from the control sample with or without phenolics present $(\alpha=0.05)$. It is worth noting that the proportion of correct responses increased with increasing oligosaccharide concentration when phenolics were present. Additionally, no significant difference was noticed between the GOS450 and the GOS900 samples. However, the results did show a significant difference $(\alpha=0.05)$ between the FOS450 and FOS900 samples in the initial triangle test. Additionally, the GOS900 sample was incredibly close to significance when added with phenolics, p-value $=0.056$. 
Table 2. Initial Triangle Test Results

\begin{tabular}{lllll}
\hline Comparison & Number of Participants & Number of Correct Responses & Z-Score & p-value \\
\hline Control v. FOS 450 & 90 & 36 & 1.23 & 0.109 \\
Control v. FOS 900 & 90 & 29 & -0.34 & 0.633 \\
FOS 450 v. FOS 900 & 90 & 39 & 1.90 & $0.029^{*}$ \\
Control v. GOS 450 & 90 & 28 & -0.56 & 0.712 \\
Control v. GOS 900 & 90 & 27 & -0.78 & 0.782 \\
GOS 450 v. GOS 900 & 90 & 35 & 1.01 & 0.156 \\
\hline
\end{tabular}

*Significance at $\alpha=0.05$

Table 3. Secondary Triangle Test Results

\begin{tabular}{lllll}
\hline Comparison & Number of Participants & Number of Correct Responses & Z-Score & p-value \\
\hline Control + Phenols v. FOS 450 & 75 & 19 & -1.59 & 0.944 \\
Control + Phenols v. FOS 900 & 75 & 25 & -0.12 & 0.548 \\
Control + Phenols v. GOS 450 & 75 & 22 & -0.86 & 0.805 \\
Control + Phenols v. GOS 900 & 75 & 32 & 1.59 & 0.056 \\
\hline
\end{tabular}

*Significance at $\alpha=0.05$

\subsection{Descriptive Analysis}

ANOVA and Tukey Cramer HSD pairwise comparisons revealed no significant differences in any of the treatment groups for any of the attributes evaluated. However, a few notable trends were noticed and can be seen in Figure 1. Interestingly, sweetness appeared to increase slightly in all the treatments when compared to the control. This is interesting as preliminary tastings (data not shown) did not indicate any difference in sweetness intensity. Bitterness was reduced for each of the GOS treatments (particularly GOS900) and reduced bitterness perception more than FOS. Perceived astringency increased with each treatment except for GOS900 which had an average lower astringency than the treatments or control. Viscosity increased with both FOS treatments, and the GOS900 treatment. Finally, acidity increased with all four treatments, with the FOS treatments increasing acidity perception more than the GOS treatments.

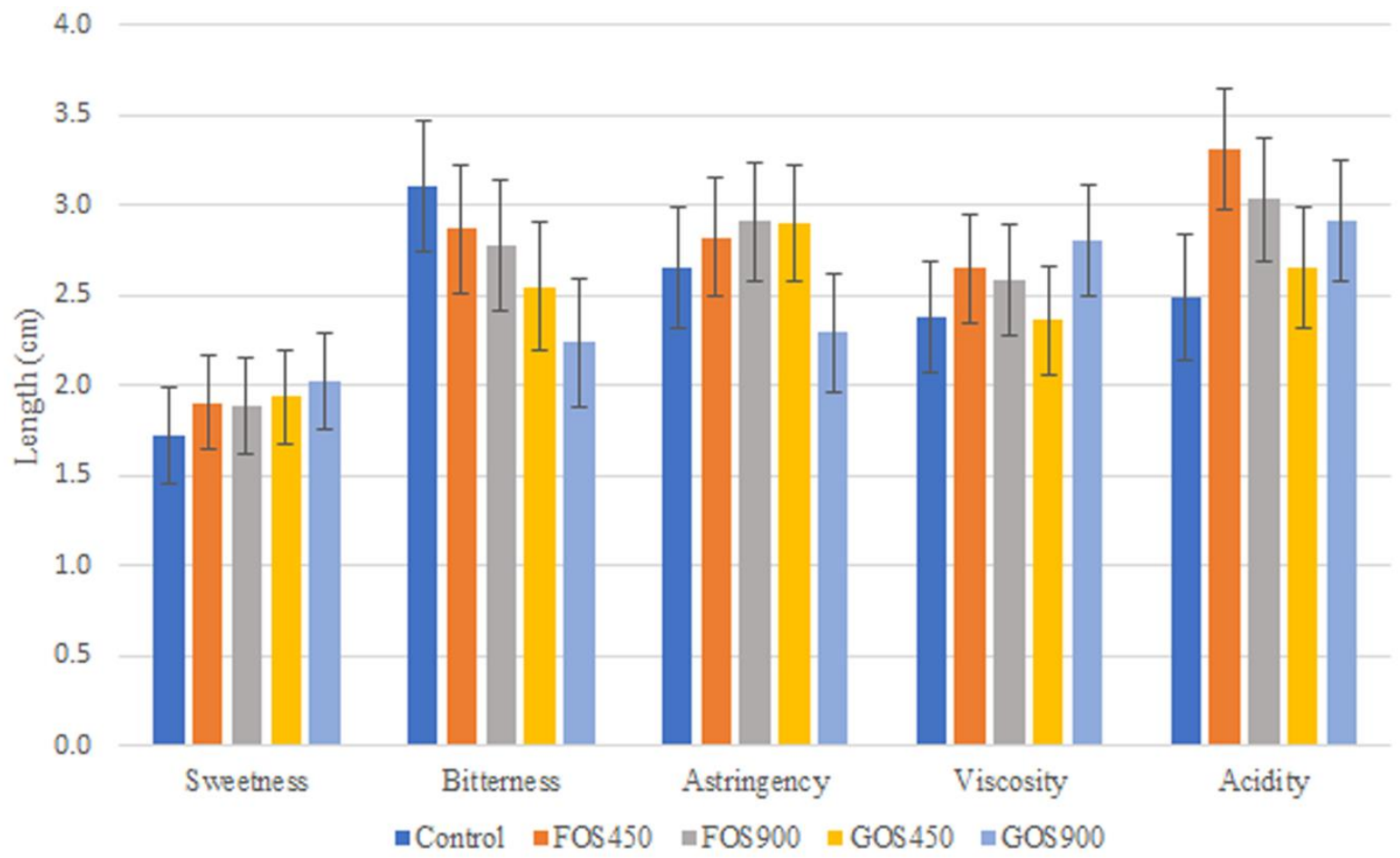

Figure 1. Descriptive analysis results by attribute for model wine with different concentrations $(450 \mathrm{mg} / \mathrm{L}$ or $900 \mathrm{mg} / \mathrm{L})$ of FOS or GOS 


\section{Discussion}

\subsection{Discussion}

For both FOS and GOS, the tests between the higher and lower concentrations had a higher proportion of correct responses than any of the concentrations versus the control. Except for FOS450, and while not statistically significant, FOS450 sample versus the control was in fact close to significance at a lower alpha level of $\alpha=0.10$. It is worth noting that the same is true for the GOS450 versus GOS900 at an alpha level of $\alpha=0.15$. These results indicate that a change in perception is occurring, but it is not large enough to be obvious. The change in taste and mouthfeel perception may be due to interactions between oligosaccharides and other compounds in saliva. Previous studies have demonstrated oral enzymatic activity, such as $\alpha$-amylase activity, can incite oral digestion of starches into malto-oligosaccharides and alter taste perception. (Robyt, 2009; Roberts \& Whelan, 1960; Whelan \& Roberts, 1952). Such enzymatic activity could increase the presence of carbohydrate monomers within the mouth due to the breakdown of oligosaccharides. This phenomenon might also explain the trend of increased sweetness perception noticed during the descriptive analysis.

While descriptive analysis did not yield statistically significant results some trends can be seen. As mentioned previously there appears to be a slight increase in sweetness perception for all treatments containing FOS or GOS. There is evidence to suggest that more complex carbohydrates are perceived as sweet (Lapis et al., 2014, 2016; Low et al., 2017; Pullicin et al., 2017, 2019; Ruiz-Aceituno et al., 2018). This sweetness perception varies depending on mDP and compound structure (Low et al., 2017; Pullicin et al., 2017). Additionally, sweetness of complex carbohydrates has been shown to be independent of enzymatic activity or hT1R2/hT1R3 receptor (Lapis et al., 2016; Yoon \& Robyt, 2003). While these studies used different oligosaccharide types in a simpler system (water), they clearly show that oligosaccharides can elicit a sweet response. The trend of increased sweetness in all FOS and GOS samples within the descriptive analysis in our experiment is consistent with these findings.

The trend noted in viscosity perception could be explained by oligosaccharide size. Chong et al., (2019) found that soluble cell wall carbohydrates may play a role in mouthfeel perception, specifically viscosity, of Cabernet Sauvignon. Further, Gawel et al., (2016) noted polysaccharides had a small effect on mouthfeel specifically medium molecular mass polysaccharides, on wine viscosity at a higher $\mathrm{pH}$. $\mathrm{mDP}$ and inulin concentration can impact rheological measurements in low-fat yogurt, leading to perceived changes in "thick", "airy", and "sticky" attributes. These terms are often associated with increased viscosity (Kip et al., 2006). Our findings provide further support, as the presence of oligosaccharides increased viscosity perception compared to the control in all treatments except GOS450.

The decreased bitterness in all oligosaccharide treatments is likely due to the increased sweetness perception, given sweet tastes have been found to mask bitterness in certain food systems (Hutchings et al., 2016; Mastaneh et al., 2013). Although this has not been explored specifically within a wine system, it is likely that similar perception changes would occur in wine. The lack of significant findings from the descriptive analysis tests might be due to differences in delivery mechanism. Previous oligosaccharide sweetness studies utilized water-based oligosaccharide solutions, while the present study employed oligosaccharides solubilized in a more complex wine matrix (Lapis et al., 2014, 2016; Low et al., 2017; Pullicin et al., 2017, 2019; Ruiz-Aceituno et al., 2018). This complex matrix could make discrimination test more difficult, particularly if the differences between treatments were more nuanced.

Interestingly, initial triangle test results revealed statistically significant differences between the FOS450 and FOS900 treatments only but not between either sample or the control. This lack of difference from the control rules out that the detection threshold of the oligosaccharide played a role in the difference noted between the two concentrations. Thus, another phenomenon must be at work within the system resulting in the statistically significant difference. Descriptive analysis results indicated FOS450 and FOS900 samples differ most in their acidity perception. This may be due to what many wine experts and consumers refer to as wine balance. While the definition of wine balance varies, it is generally referred to a holistic attribute with multiple components (Green et al., 2011; Parr et al., 2011). The increased carbohydrate concentration between FOS450 and FOS900 could alter the wine balance, explaining both the trends noticed in acidity perception and the decreased bitterness perception.

In the triangle tests where polyphenols were added, there were no significant differences noticed between any of the treatments and the control. While the proportion of correct responses increased for both FOS and GOS, these trends were not of statistical significance. This indicates that the concentrations tested are below a detection threshold for most consumers. Utilizing higher concentrations of oligosaccharides could result in more 
perceivable differences. However, this study included oligosaccharide concentrations above levels previously reported in wine in order to tease out potential differences and higher concentrations would not be possible without significant changes to the extraction process which are outside the scope of typical winemaking.

Currently our understanding of oligosaccharide effects on organoleptic perception has mostly focused on astringency perceptions. Quijada-Morín et el. (2021) concluded that while astringency was positively related to mannose and galactose in the oligosaccharide faction, this was most likely due to the reduction in mannoproteins and polysaccharides rich in arabinose and galactose rather than the glycoside residues While not statistically significant, the positive correlation between astringency perception and oligosaccharide concentration is in agreement with Boulet et al., (2016). However, when polyphenols known to influence astringency (Ferrer-Gallego et al., 2014) were added to the base model wine solution, no difference was noticed. Trends were noticed during the descriptive analysis, and differences found via the initial triangle testing. The present study suggests that oligosaccharides, specifically fructo-oligosaccharides and galacto-oligosaccharides, do not have a significant influence on the taste and mouthfeel of wine and are an irrelevant factor in the winemaking process.

\subsection{Limitations}

Given the limited available literature, there was little previous knowledge in terms, established attributes, and training standards. Thus, a broad approach to the descriptive analysis training was utilized to encompass all possible responses. Due to this approach, the training standards included high concentration standards that panelists may have felt did not accurately represent the scale that the samples fell under.

Additionally, due to increased COVID-19 restrictions imposed by the state of Oregon (Executive Order 20-65) on November 17th, 2020, the training and testing schedule was shortened. This shortened training time resulted in less overall attribute training and could account for greater variability in the descriptive analysis.

\subsection{Future Work}

Future work should look at additional oligosaccharide types and interactions with other compounds, as different types could be perceived differently. Longer training using lower concentration standards should be conducted to help reduce variance in descriptive analysis.

\subsection{Conclusion}

Oligosaccharides appear to have very minor effects on taste and mouthfeel perception within a wine system. Statistically significant differences were found between the high and low concentrations of Fructo-oligosaccharides. None of the concentrations were found to be significantly different from the control samples in either of the triangle tests. Given that there was a significant difference found between the two Fructo-oligosaccharide samples in the first test, and not the controls in either test, it would appear there are more complex systems at work. This is illustrated by the trends noticed in descriptive analysis. These trends show an increase in sweetness and acidity perception, a decrease in bitterness, and differences in viscosity and astringency dependent upon concentration. While the trends are apparent in descriptive analysis, given the lack of differences noticed in both triangle tests, oligosaccharides do not play a large role in wine perception, and we do not recommend focusing on them during the winemaking process.

\section{Acknowledgments}

We would like to acknowledge Aubrey DuBois for her help in editing this manuscript.

\section{References}

Apolinar-Valiente, R., Romero-Cascales, I., Gómez-Plaza, E., López-Roca, J. M., \& Ros-García, J. M. (2015). The composition of cell walls from grape marcs is affected by grape origin and enological technique. Food Chemistry, 167, 370-377. https://doi.org/10.1016/j.foodchem.2014.07.030

Apolinar-Valiente, R., Williams, P., Mazerolles, G., Romero-Cascales, I., Gómez-Plaza, E., López-Roca, J. M., Ros-García, J. M., \& Doco, T. (2014). Effect of enzyme additions on the oligosaccharide composition of Monastrell red wines from four different wine-growing origins in Spain. Food Chemistry, 156, 151-159. https://doi.org/10.1016/j.foodchem.2014.01.093

Apolinar-Valiente, R., Williams, P., Romero-Cascales, I., Gómez-Plaza, E., López-Roca, J. M., Ros-García, J. M., \& Doco, T. (2013). Polysaccharide Composition of Monastrell Red Wines from Four Different Spanish Terroirs: Effect of Wine-Making Techniques. Journal of Agricultural and Food Chemistry, 61(10), 2538-2547. https://doi.org/10.1021/jf304987m

BeMiller, J. N. (2019). Oligosaccharides (3rd ed.). Carbohydrate Chemistry for Food Scientists. 
https://doi.org/10.1016/B978-0-12-812069-9.00003-0

Bordiga, M., Travaglia, F., Meyrand, M., German, J. B., Lebrilla, C. B., Coïsson, J. D., Arlorio, M., \& Barile, D. (2012). Identification and Characterization of Complex Bioactive Oligosaccharides in White and Red Wine by a Combination of Mass Spectrometry and Gas Chromatography. Journal of Agricultural and Food Chemistry, 60(14), 3700-3707. https://doi.org/10.1021/jf204885s

Boulet, J.-C., Trarieux, C., Souquet, J.-M., Ducasse, M.-A., Caillé, S., Samson, A., Williams, P., Doco, T., \& Cheynier, V. (2016). Models based on ultraviolet spectroscopy, polyphenols, oligosaccharides and polysaccharides for prediction of wine astringency. Food Chemistry, 190, 357-363.

https://doi.org/10.1016/j.foodchem.2015.05.062

Chong, H. H., Cleary, M. T., Dokoozlian, N., Ford, C. M., \& Fincher, G. B. (2019). Soluble cell wall carbohydrates and their relationship with sensory attributes in Cabernet Sauvignon wine. Food Chemistry, 298, 124745. https://doi.org/10.1016/j.foodchem.2019.05.020

Deffert, F., Agustini, B. C., Picheth, G., \& Bonfim, T. M. B. (2017). Screening of whole yeast free-cells and optimization of $\mathrm{pH}$ and temperature for fructooligosaccharides production. Acta Scientiarum. Biological Sciences, 39(2), 189-194. https://doi.org/10.4025/actascibiolsci.v39i2.34140

Ducasse, M.-A., Williams, P., Canal-Llauberes, R.-M., Mazerolles, G., Cheynier, V., \& Doco, T. (2011). Effect of Macerating Enzymes on the Oligosaccharide Profiles of Merlot Red Wines. Journal of Agricultural and Food Chemistry, 59(12), 6558-6567. https://doi.org/10.1021/jf2003877

Ducasse, M.-A., Williams, P., Meudec, E., Cheynier, V., \& Doco, T. (2010). Isolation of Carignan and Merlot red wine oligosaccharides and their characterization by ESI-MS. Carbohydrate Polymers, 79(3), 747-754. https://doi.org/10.1016/j.carbpol.2009.10.001

Ferrer-Gallego, R. Hernández-Hierro, J.M. Rivas-Gonzalo, J.C., \& Escribano-Bailón, M.T. (2014). Sensory Evaluation of Bitterness and Astringency sub-qualities of Wine Phenolic Compounds: Synergistic Effect and Modulation by Aromas. Food Research Journal, 62, 1100-1107. https://doi.org/10.1016/j.foodres.2014.05.049

Gawel, R., Oberholster, A., \& Francis, I. L. (2000). A 'Mouth-feel Wheel': Terminology for communicating the mouth-feel characteristics of red wine. Australian Journal of Grape and Wine Research, 6(3), 203-207. https://doi.org/10.1111/j.1755-0238.2000.tb00180.x

Green, J. A., Parr, W. V., Breitmeyer, J., Valentin, D., \& Sherlock, R. (2011). Sensory and chemical characterisation of Sauvignon blanc wine: Influence of source of origin. Food Research International, 44(9), 2788-2797. https://doi.org/10.1016/j.foodres.2011.06.005

Huang, R., \& Xu, C. (2021). An overview of the perception and mitigation of astringency associated with phenolic compounds. Comprehensive Reviews in Food Science and Food Safety, 20(1), 1036-1074. https://doi.org/10.1111/1541-4337.12679

ISO 4120. (2004). Sensory Analysis-Methodology-Triangle Test. International Organization for Standardization.

Kip, P., Meyer, D., \& Jellema, R. H. (2006). Inulins improve sensoric and textural properties of low-fat yoghurts. International Dairy Journal, 16(9), 1098-1103. https://doi.org/10.1016/j.idairyj.2005.10.011

Laguna, L., Bartolomé, B., \& Moreno-Arribas, M. V. (2017). Mouthfeel perception of wine: Oral physiology, components and instrumental characterization. Trends in Food Science \& Technology, 59, 49-59. https://doi.org/10.1016/j.tifs.2016.10.011

Lapis, T. J., Penner, M. H., \& Lim, J. (2014). Evidence that Humans Can Taste Glucose Polymers. Chemical Senses, 39(9), 737-747. https://doi.org/10.1093/chemse/bju031

Lapis, T. J., Penner, M. H., \& Lim, J. (2016). Humans Can Taste Glucose Oligomers Independent of the hT1R2/hT1R3 Sweet Taste Receptor. Chemical Senses, 41(9), 755-762.

https://doi.org/10.1093/chemse/bjw088

Low, J. Y. Q., Lacy, K. E., McBride, R. L., \& Keast, R. S. J. (2017). Evidence supporting oral sensitivity to complex carbohydrates independent of sweet taste sensitivity in humans. PloS One, 12(12), e0188784-e0188784. https://doi.org/10.1371/journal.pone.0188784

Osborne, J., Ring, L., Tomasino, E., \& Qian, Q. (2019). Diversity of total carbohydrate composition in red wine polysaccharides in several Pinot noirs and other varieties. 70th ASEV National Conference, Napa, CA. 
Parr, W. V., Mouret, M., Blackmore, S., Pelquest-Hunt, T., \& Urdapilleta, I. (2011). Representation of complexity in wine: Influence of expertise. Food Quality and Preference, 22(7), 647-660. https://doi.org/10.1016/j.foodqual.2011.04.005

Pickering, GaryJ., \& Demiglio, P. (2008). The White Wine Mouthfeel Wheel: A Lexicon for Describing the Oral Sensations Elicited by White Wine. Journal of Wine Research, 19(1), 51-67. https://doi.org/10.1080/09571260802164038

Pullicin, A. J., Penner, M. H., \& Lim, J. (2017). Human taste detection of glucose oligomers with low degree of polymerization. PloS One, 12(8), e0183008-e0183008. https://doi.org/10.1371/journal.pone.0183008

Pullicin, A. J., Penner, M. H., \& Lim, J. (2019). The Sweet Taste of Acarbose and Maltotriose: Relative Detection and Underlying Mechanism. Chemical Senses, 44(2), 123-128. https://doi.org/10.1093/chemse/bjy081

Quijada-Morín, N., Williams, P., Rivas-Gonzalo, J. C., Doco, T., \& Escribano-Bailón, M. T. (2014). Polyphenolic, polysaccharide and oligosaccharide composition of Tempranillo red wines and their relationship with the perceived astringency. Food Chemistry, 154, 44-51. https://doi.org/10.1016/j.foodchem.2013.12.101

Roberts, P. J. P., \& Whelan, W. J. (1960). The mechanism of carbohydrase action. 5. Action of human salivary $\alpha$-amylase on amylopectin and glycogen. Biochemical Journal, 76(2), 246-253. https://doi.org/10.1042/bj0760246

Robyt, J. F. (2009). Chapter 7 Enzymes and Their Action On Starch. In J. N. BeMiller (Ed.), Starch Chemistry and Technology (pp. 237-292). Academic Press, San Diego, USA. https://doi.org/10.1016/B978-0-12-746275-2.00007-0

Ruiz-Aceituno, L., Hernandez-Hernandez, O., Kolida, S., Moreno, F. J., \& Methven, L. (2018). Sweetness and sensory properties of commercial and novel oligosaccharides of prebiotic potential. Food Science \& Technology, 97, 476-482. https://doi.org/10.1016/j.lwt.2018.07.038

Sarneckis, C. J., Dambergs, R. G., Jones, P., Mercurio, M., Herderich, M. J., \& Smith, P. A. (2006). Quantification of condensed tannins by precipitation with methyl cellulose: Development and validation of an optimised tool for grape and wine analysis. Australian Journal of Grape and Wine Research, 12(1), 39-49. https://doi.org/10.1111/j.1755-0238.2006.tb00042.x

Sparrow, A. M., Holt, H. E., Pearson, W., Dambergs, R. G., \& Close, D. C. (2016). Accentuated Cut Edges (ACE): Effects of Skin Fragmentation on the Composition and Sensory Attributes of Pinot noir Wines. American Journal of Enology and Viticulture, 67(2), 169-178. https://doi.org/10.5344/ajev.2015.15094

Merriam-Webster (n.d.) Sweet Definition of Sweet by Merriam-Webster. Retrieved from https://www.merriam-webster.com/dictionary/sweet

Vicens, A., Fournand, D., Williams, P., Sidhoum, L., Moutounet, M., \& Doco, T. (2009). Changes in Polysaccharide and Protein Composition of Cell Walls in Grape Berry Skin (Cv. Shiraz) during Ripening and Over-Ripening. Journal of Agricultural and Food Chemistry, 57(7), 2955-2960. https://doi.org/10.1021/jf803416w

Whelan, W. J., \& Roberts, P. J. P. (1952). Action of Salivary $\alpha$-Amylase on Amylopectin and Glycogen. Nature (London), 170(4331), 748-749. https://doi.org/10.1038/170748a0

Williamson, P. (2013). Sensory descriptive analysis on commercial wines of varied styles. The Australian Wine Research Institute. p. 10. Retrieved from https://www.wineaustralia.com/getmedia/7493a91f-2144-4ded-97b5-dda3d50cdf96/Appendix-I-Sensory

Yoon, S.-H., \& Robyt, J. F. (2003). Study of the inhibition of four alpha amylases by acarbose and its 4IV-alpha-maltohexaosyl and 4IV-alpha-maltododecaosyl analogues. Carbohydrate Research, 338(19), 1969-1980. https://doi.org/10.1016/S0008-6215(03)00293-3

Zietsman, A. J. J., Moore, J. P., Fangel, J. U., Willats, W. G. T., Trygg, J., \& Vivier, M. A. (2015). Following the Compositional Changes of Fresh Grape Skin Cell Walls during the Fermentation Process in the Presence and Absence of Maceration Enzymes. Journal of Agricultural and Food Chemistry, 63(10), 2798-2810. https://doi.org/10.1021/jf505200m 


\section{Copyrights}

Copyright for this article is retained by the author(s), with first publication rights granted to the journal.

This is an open-access article distributed under the terms and conditions of the Creative Commons Attribution license (http://creativecommons.org/licenses/by/4.0/). 